\title{
PREDICTION OF BRONCHIECTASIS DEVELOPMENT RISK IN CHILDREN WITH CYSTIC FIBROSIS
}

\author{
Klymenko V., Drobova N.
}

\author{
Kharkiv National Medical University, Ukraine
}

\begin{abstract}
Cystic fibrosis (CF) is a genetic disease with a multiple organ type of lesion and life-threatening respiratory disorder. The purpose of the study was to improve medical care for patients with $\mathrm{CF}$ by treatment individualization according to the prediction of the respiratory tract complications development. The study involved 42 children with CF. Patients were divided into 2 groups: main (with bronchiectasis) and control (without bronchiectasis) group. One hundred twelve clinical and paraclinical indices were analyzed. After that the logistic regression method with step-by-step incorporation of predictors was used to analyze the features and to select meaningful criteria for prognosis. The mathematical model for predicting bronchiectasis development in children with CF was created. It should help to make an individual algorithm for treatment using non-specific research methods in order to prevent the progression of morphological changes in the respiratory tract in patients with CF.

Key words: children, cystic fibrosis, bronchiectasis, mathematical model, predicting.
\end{abstract}

Introduction. Cystic fibrosis (CF) is a genetic disease, which is caused by mutation of the cystic fibrosis transmembrane conductance regulator (CFTR) protein with involvement of the exocrine glands of vital organs and systems [1-4].

CF affects a variety of organs, but especially involving respiratory tract and pancreas [5]. The lungs undergo gradual destruction, as an effect of persistent microbial colonization, chronic inflammation and recurrent infections caused by highly pathogenic bacteria, such as Pseudomonas aeruginosa and Staphylococcus aureus (S. aureus), as well as Hemophilus influenzae, Stenotrophomonas maltophilia, Achromobacter xylosoxidans, Burkholderia cepacia ñomplex etc. Several constituents of the innate immunity are also affected by the disease [6]. As a consequence, despite the amazing progress in treating CF-related lung disease, it still accounts for nearly $85 \%$ of the mortality [7].

The airways of the affected lungs are clogged by purulent secretions and deformed due to the development of bronchiectatic lesions, while in the parenchyma the formation of multiple cavitations or cysts, areas of bronchiolar

Corresponding Author:

Nadiia Drobova, MD PhD student,

Department of Fundamentals of Pediatrics No. 2, Kharkiv National Medical University, Ukraine.

E-mail:dn88n5@gmail.com consolidation, fibrosis and air-trapping compromise respiratory adequacy [8]. Bronchiectasis has a highly variable clinical presentation, as it is a disorder that can affect any age from young children to the very elderly, males and females, and it is present in all ethnic groups [9]. As such, it is not possible to describe a single typical clinical presentation [10]. Bronchiectasis is a chronic airway disease that has increased in prevalence over the past decade and is associated with growing morbidity and mortality rates worldwide [11]. As a complex multicomponent disease, bronchiectasis is characterized by chronic systemic inflammation that frequently coexists with comorbidities, which might be causative, synergistic, or coincidental, depending on how they interact $[12,13]$.

Bronchiectasis is a marker of severe cystic fibrosis course. Modern medical protocols for medical care to patients with CF include a large number of medications aimed at various parts of pathogenesis of the disease and affect the various systems of the organism [14]. Predicting the development of this pathology should improve the life quality of patients with CF.

\section{PURPOSES, SUBJECTS and} METHODS:

2.1. Purpose - to improve medical care for patients with CF by treatment individualization according to the prediction of the respiratory tract complications development. 
2.2. Subjects \& Methods. The research was conducted in the pulmonology department of the Kharkiv Regional Clinical Children's Hospital No 1 in 2015-2017. Clinical and paraclinical examination of patient with CF were carried out according to the Order of Ministry of Healthcare of Ukraine as of 15 July 2016 No. 723 "On approval of the unified clinical protocol of primary, secondary (specialized) and tertiary (highly specialized) medical care "Cystic fibrosis", Order of Ministry of Healthcare of Ukraine as of 29 January 2013 No. 59 "On approval of unified clinical protocols of medical care for children with diseases of the digestive system".

Patients with CF were divided into 2 groups: main (with bronchiectasis) and control (without bronchiectasis). One hundred twelve indices were analyzed (passport data (age), presentation, present and past history, clinical signs of organs and systems lesions, laboratory and instrumental research results (blood and urine analysis, coprogram, spirography, electrocardiography, computed tomography of the chest, ultrasound examination of the abdominal cavity, bacteriological examination of sputum, bronchial washings, immunological parameters and total immunoglobulin E, data of allergy testing, etc.). The logistic regression method with the step-bystep incorporation of predictors was used to analyze the features and to select meaningful criteria for the mathematical model creation. Mathematical processing of the results was carried out using the SPSS 23 softwaare for Windows

The study was conducted with respect to human rights in accordance with the legislation in force in Ukraine, in compliance with international ethical requirements and did not violate ethical norms in science and standards for conducting biomedical research.

Conflict of interests. There is no conflict of interests.
3. Results and discussion. The study involved examination of 42 children. Diagnosis of CF was based on clinical and paraclinical characteristics and confirmed by the results of pilocarpine test.

Main group included 17 patients with bronchiectasis and control group comprised 25 patients. There were predominantly girls in the main group $(52.9 \%, \mathrm{p}=0.055)$.

According to age, the majority were children of senior school age (table 1).

CF manifestation was represented by the gastrointestinal signs prevalence without a significant difference between the main and control groups $(76.4 \%$ vs $72.0 \%, p=0.746$ respectively).

In the majority of main group, the first gastrointestinal signs of the disease were identified during neonatal period (52.9\%), compared with the control group (in infant period $68.3 \%, \mathrm{p}=0.340$ ).

Regarding the symptoms of the respiratory system for patients with bronchiectasis, there was a tendency for their later manifestation - in preschool period (52.9\%) compared with the control group (in infant period $-(48.0 \%, \mathrm{p}=0.585)$.

The sweat chloride test results of the main group were significantly higher $(123.7 \pm$ $7.18 \mathrm{mmol} / \mathrm{l}$ ) compared with the control group $(93.8 \pm 5.15 \mathrm{mmol} / \mathrm{l}, \mathrm{p}=0.034)$.

The spirography was defined in children over 5 years $(n=31)$ and showed significant decrease in the examination basic parameters (table 2).

The incidence of lung fibrosis $(100 \%)$ was significantly higher $(p=0.003)$ in the main group. Typical bronchiectasis of patients with CF is shown on Figure.

Assessment of bacteriological tests showed that Pseudomonas aeruginosa (64.7 \% vs $24.0 \%$, $\mathrm{p}=0.014$ ), S. aureus (76.4 \% vs $40.0 \%, \mathrm{p}=0.028)$, Alcaligenes faecalis $(23.4 \%$ vs $0 \%, \mathrm{p}=0.025)$ were significantly more common in the main group patients.

Table 1

Distribution of children with CF and bronchiectasis by age

\begin{tabular}{|c|c|c|c|c|c|c|c|c|c|}
\hline \multirow{2}{*}{ Group } & \multicolumn{2}{|c|}{$\begin{array}{c}1 \text { year }- \\
2 \text { year } \\
11 \text { months } \\
29 \text { days }\end{array}$} & \multicolumn{2}{|c|}{$\begin{array}{c}3 \text { years }- \\
6 \text { years } \\
11 \text { months } \\
29 \text { days }\end{array}$} & \multicolumn{2}{|c|}{$\begin{array}{c}7 \text { years }- \\
11 \text { years } \\
11 \text { months } \\
29 \text { days }\end{array}$} & \multicolumn{2}{|c|}{$\begin{array}{c}12 \text { years - } \\
17 \text { years } \\
11 \text { months } \\
29 \text { days }\end{array}$} & \multirow{2}{*}{$\begin{array}{c}\text { Total } \\
\mathrm{n}\end{array}$} \\
\hline & $\mathrm{n}$ & $\%$ & $\mathrm{n}$ & $\%$ & $\mathrm{n}$ & $\%$ & $\mathrm{n}$ & $\%$ & \\
\hline Main & 3 & 17.6 & 3 & 17.6 & 3 & 17.6 & 8 & 47.2 & 17 \\
\hline Control & 1 & 4.0 & 3 & 12.0 & 11 & 44.0 & 10 & 40.0 & 25 \\
\hline Total & 4 & 9.5 & 6 & 14.2 & 14 & 33.4 & 18 & 42.9 & 42 \\
\hline
\end{tabular}


Spirography test in children with CF

\begin{tabular}{|l|c|c|c|}
\hline \multicolumn{1}{|c|}{$\begin{array}{c}\text { Spirography } \\
\text { indices }\end{array}$} & $\begin{array}{c}\text { Main group } \\
(\mathrm{n}=14)\end{array}$ & $\begin{array}{c}\text { Control group } \\
(\mathrm{n}=17)\end{array}$ & $\mathrm{p}$ \\
\hline VC, \% & $66.5(62.25 ; 68.25)$ & $71.0(67.0 ; 80.0)$ & 0.013 \\
\hline FVC, \% & $65.0(59.0 ; 69.0)$ & $69,0(67.5 ; 80.5)$ & 0.010 \\
\hline FEV1, \% & $70.0(65.0 ; 74.0)$ & $72,0(70.5 ; 82.0)$ & 0.101 \\
\hline
\end{tabular}

The study of the liver parenchyma impairment showed that the incidence of cirrhotic lesions of the liver parenchyma was significantly higher in the main group compared to the control (41.2\% vs $8.0 \%$, ठ $=0.011$ ).

Features of immune status in children with CF and bronchiectasis are presented in Table 3. There was a significant increase in phagocytosis of latex, lymphocytes, spontaneous nitroblue
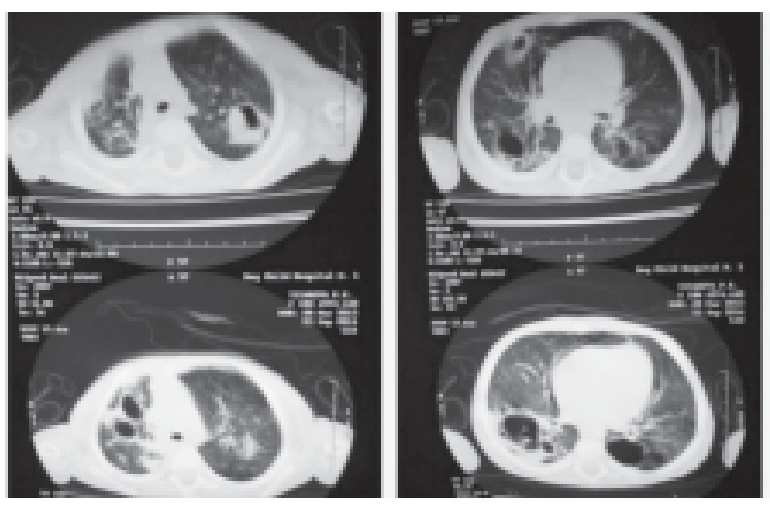

Bronchiectasis in the child with CF parenchyma; yes).
$\tilde{\mathrm{O}}_{1}$ - phagocytosis of latex (\%);

$\tilde{\mathrm{O}}_{2}$ - sweat chloride level (mmol/l);

$\tilde{\mathrm{O}}_{3}^{2}-$ evaluation of liver parenchyma according to ultrasound examination (1- norm, 2 - increased liver echodensity at ultrasound examination, 3 - cirrhotic lesions of the liver

$\tilde{\mathrm{O}}_{4}-\mathrm{S}$. aureus (in sputum) $(1-$ no, $2-$
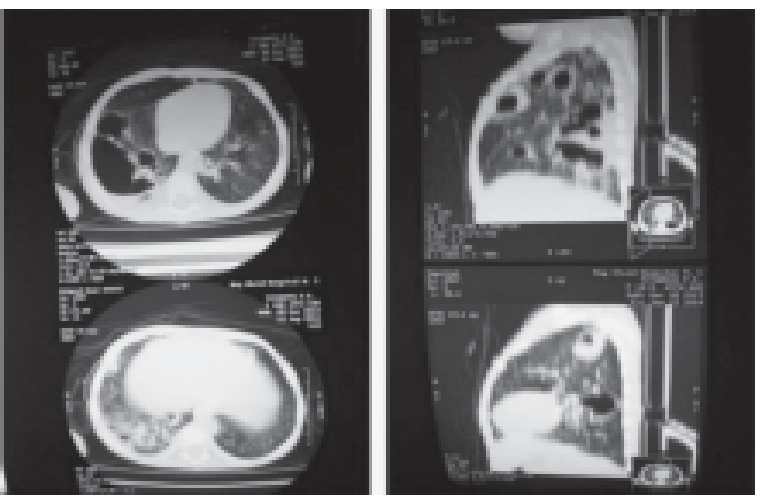

The $P$ value is in the range from 0 to 1 and tetrazolium tests, spontaneous index of activated neutrophils test decreasing compared with the control.

Thus, observation of patients with CF and bronchiectasis has revealed a number of clinical and laboratory signs regarding the prediction of morphological changes in the respiratory tract. Using simple methods of nonparametric statistics during definition of significant conclusions is complicated by the rarity of the pathology and a little number of patients. Therefore, to objectivize the evaluation of the individual factors influence in bronchiectasis pathogenesis in CF, a logistic regression method was used to determine the coefficients of regression function.

After the mathematical model formation, the logistic regression equation, which determines the probability of bronchiectasis developing in children with CF, has the following form:

$Đ=\left[1+\exp \left(-\left(0,316 \times \tilde{\mathrm{O}}_{1}+0,083 \times \tilde{\mathrm{O}}_{2}+\right.\right.\right.$ $\left.\left.\left.+4,009 \times \tilde{O}_{3}+6,778 \times \tilde{O}_{4}-43,372\right)\right)\right]-1$, where

$Đ$ - the risk factor for the bronchiectasis development in a child with CF; reflects the probability of the risk of bronchiectasis formation in a child with CF. If $\mathrm{P} \geq 0.5$, it predicts a high risk of bronchiectasis formation, and if $\mathrm{P}<0.5$, it predicts a low risk of bronchiectasis formation.

All variables, according to Wald test, are significant $(\mathrm{p}<0.05)$ and are selected correctly. The overall assessment of the coincidence between the identified risk factors in the model and the actual observed adverse event was conducted using the Hosmer and Lemeshow test, the accuracy of the classification was $95.2 \%$.

The effectiveness of the proposed mathematical model is illustrated by the following clinical case.

A 12-year-old boy S. was admitted to Kharkiv Regional Clinical Children's Hospital No. 1 for the preventive treatment course. The patient presented with coughing with periodic sputum of yellow color, periodic bitter taste in the oral cavity. The condition was assessed as moderate due to respiratory and gastrointestinal disorders. 
Indices of immunological status of children with CF and bronchiectasis (Median; Q1; Q3)

\begin{tabular}{|l|c|c|}
\hline \multicolumn{1}{|c|}{ Indices } & $\begin{array}{c}\text { Main group } \\
(\mathrm{n}=17)\end{array}$ & $\begin{array}{c}\text { Control group } \\
(\mathrm{n}=25)\end{array}$ \\
\hline Leukocytes, $\mathrm{x} 10^{9} / 1$ & $6.5(5.4 ; 7.05)$ & $6.0(5.0 ; 7.8)$ \\
\hline Neutrophils, \% & $50.0(42.5 ; 68.5)$ & $44.0(38.5 ; 58.0)$ \\
\hline Lymphocytes, \% & $45.0(29.0 ; 56.5)^{*}$ & $57.0(44.0 ; 63.0)$ \\
\hline CD 3, \% & $69.0(64.5 ; 70.0)$ & $68.0(64.0 ; 70.0)$ \\
\hline CD 4, \% & $40.0(38.0 ; 40.5)$ & $39.0(38.0 ; 41.0)$ \\
\hline CD 8, \% & $27.0(25.0 ; 28.5)$ & $28.0(26.5 ; 29.0)$ \\
\hline CD 16, \% & $13.0(9.5 ; 15.5)$ & $14.0(10.0 ; 18.0)$ \\
\hline CD 22, \% & $19.0(18.0 ; 20.0)$ & $18.0(16.0 ; 21.0)$ \\
\hline CD 25, \% & $21.0(18.0 ; 29.5)$ & $22.0(18.5 ; 37.0)$ \\
\hline Phagocytosis of latex, \% & $69.0(58.0 ; 74.0)^{*}$ & $63.0(56.5 ; 68.0)$ \\
\hline Phagocytic number & $3.8(3.75 ; 4.1)$ & $3.8(3.7 ; 4.1)$ \\
\hline Total complement $(\mathrm{CH} 50)$ & $64.0(62.0 ; 67.5)$ & $64.0(60.5 ; 66.0)$ \\
\hline $\begin{array}{l}\text { Circulating immune complexes } \\
\text { with 3.5\% PEG, units }\end{array}$ & $8.1(7.3 ; 10.1)$ & $7.7(6.25 ; 9.25)$ \\
\hline $\begin{array}{l}\text { Spontaneous nitroblue tetrazolium } \\
\text { (NBT) tests, \% }\end{array}$ & $16.0(12.0 ; 28.0)^{*}$ & $33.0(18.0 ; 47.0)$ \\
\hline $\begin{array}{l}\text { Spontaneous index of activated } \\
\text { neutrophils (IAN) test, units }\end{array}$ & $0.3(0.21 ; 0.55)^{*}$ & $0.69(0.32 ; 0.92)$ \\
\hline Stimulated NBT test, \% & $65.0(59.0 ; 72.0)$ & $63.0(56.0 ; 69.0)$ \\
\hline Stimulated IAN test, units & $1.34(1.07 ; 1.48)$ & $1.34(1.17 ; 1.49)$ \\
\hline Lysosomal cationic proteins, units & $1.18(1.09 ; 1.24)$ & $1.18(0.98 ; 1.23)$ \\
\hline Ig A, g/1 & $1.29(1.07 ; 1.64)$ & $1.38(0.99 ; 1.54)$ \\
\hline Ig M, g/l & $1.02(0.9 ; 1.22)$ & $0.92(0.81 ; 1.22)$ \\
\hline Ig G, g/1 & $10.38(10.25 ; 10.76)$ & $10.36(9.9 ; 10.93)$ \\
\hline Ig E, g/1 & $86.2(28.1 ; 486.1)$ & $56.0(27.1 ; 178.4)$ \\
\hline
\end{tabular}

$* \mathrm{p}<0.05$ - compared with the control group

The child was from the second pregnancy, after 40 weeks of gestation by first vaginal delivery with a birth weight of $2800 \mathrm{gm}$, height of $46 \mathrm{~cm}$.

From the age of 6 months the mother took notice of cough, which was initially dry, then with sputum of whitish color. At the age of 8 months the child had pneumonia with prolonged severe course. After recovery, the child was referred for a medical genetic center, where CF was diagnosed based on clinical and paraclinical signs, positive sweat chloride test $(105 / 112 \mathrm{mmol} / \mathrm{l})$ at the age of 1 year 2 months.

At the age of 2 years, CFTR genotyping was performed and a carrier delF508 in a compound with an unidentified CFTR gene mutation was found.

At the age of 8 year, during the planned liver ultrasound examination, the increased liver echodensity was detected. Hepatoprotective

therapy was intensified. For 2 years, the child did not undergo preventive examination.

At the age of 10 years, signs of lung fibrosis were identified on both sides.

On examination: poor physical growth and development. Body mass index (BMI) was $15.4 \mathrm{~kg} / \mathrm{m} 2$ (equivalent to BMI $<10$ percentiles). Skin was pale. Deformation of the fingers and fingernails (clubbed fingers and watch-glass nails) were found. Thoracic cavity was the cylindrical shape. Percussion sound was shortened in back basal areas with excessive resonance in the upper and middle areas. Harsh breathing, moist small and medium bubbling rales were detected in back basal areas during lung auscultation. Heart sounds were rhythmic, sounding. Stool was 2-3 times per day.

Level of sweat chloride was $102 \mathrm{mmol} / \mathrm{l}$.

The results of laboratory studies were as follows: sputum bacteriological tests - 
S. epidemidis $10^{5}$, S. àureus $10^{6}$, C. albicans $10^{3}$; ultrasound examination of the abdominal cavity increased liver and pancreas parenchyma echodensity; immunological research - leukocytes $6,5 \times 10^{9} /$, Neutrophils $54 \%$, Lymphocytes $46 \%$, CD3 $64 \%$, CD4 $32 \%$, CD8 $40 \%$, CD16 $22 \%$, CD22 $18 \%$, CD25 $20 \%$, Phagocytosis of latex $76.0 \%$, Phagocytic number 3.9 un., Total complement (ÑII 50) $65 \%$, CIC with $3.5 \%$ PEG 9.5 un., Spontaneous NBT tests $28 \%$, Spontaneous IAN test ${ }^{2}$ ÀI $\quad 0,32$ un., Stimulated NBT test $59 \%$, Stimulated IAN test 1.04 un., Lysosomal cationic proteins 1.12 un., IgÀ 1.14 g/l, Igİ 0.96 g/l, IgG $10.21 \mathrm{~g} / \mathrm{l}$.

The calculation of the bronchiectasis development risk by using the mathematical model was done:

$\mathrm{D}=[1+\exp (-(0.316 \times 76+0.083 \times 102+4.009 \times$ $\times 2+6.778 \times 2-43.372))]-1=0.9$.
$0.9>0.5$ - conclusion was the high risk of bronchiectasis development.

The computed tomography of the chest confirmed widespread bilateral cylindrical bronchiectasis. Patient S. had bronchiectasis corresponding to the prognosis.

The mathematical model testing for patients with CF from the Dnipro Region was carried out. Efficiency was $86.7 \%$.

The mathematical model is easy to use. Its application should improve the bronchiectasis risk predicting and timely correction of therapy.

Conclusion. The mathematical model for predicting of the bronchiectasis development in children with CF was created. It should help to make an individual algorithm for treating using non-specific research methods in order to prevent the progression of morphological changes in the respiratory tract in patients with CF.

\section{References}

1. Farrell, P.M., White, T.B., Ren, C.L., Hempstead, S.E., Accurso, F., Derichs, N., Howenstine, M., McColley. S.A., Rock, M., Rosenfeld, M., Sermet-Gaudelus, I., Southern, K.W., Marshall, B.C., Sosnay, P.R. (2017). Diagnosis of Cystic Fibrosis: Consensus Guidelines from the Cystic Fibrosis Foundation. Journal of Pediatrics, 181, 4-15.e1. doi: 10.1016/j.jpeds.2016.09.064.

2. Kapranov, N.I., Kashirskaya, N.Yu. (2014). Mucoviscidoz. [Cystic Fibrosis]. Moskva: Medpraktika.

3. Dorsey, J., Gonska, T. (2017). Bacterial overgrowth, dysbiosis, inflammation, and dysmotility in the Cystic Fibrosis intestine. Journal Cystic Fibrosis, 16(2), 14-23. doi: 10.1016/j.jcf.2017.07.014

4. Ren, C. L., Fink, A. K., Petren K. et al. (2015). Outcomes of infants with indeterminate diagnosis detected by cystic fibrosis newborn screening. Journal of Pediatrics, 135, e1386-92. doi: 10.1542/peds.2014-3698

5. VanDevanter, D. R., Kahle, J. S., O'Sullivan, A. K. (2016). Cystic fibrosis in young children: a review of disease manifestation, progression, and response to early treatment. Journal Cystic Fibrosis, 15, 147-157. doi: 10.1016/j.jcf.2015.09.008

6. Kioumis, I.P., Zarogoulidis, K., Huang. H., Li, Q., Dryllis, G., Pitsiou, G., Machairiotis, N., Katsikogiannis, N., Papaiwannou, A., Lampaki, S., Porpodis, K., Zaric, B., Branislav, P., Mpoukovinas, I., Lazaridis, G., Zarogoulidis, P. (2014). Pneumothorax in cystic fibrosis. Journal of Thoracic Disease, 6(4), 480-487. doi: 10.3978/j.issn.2072-1439.2014.09.27

7. Szczesniak, R.D., McPhail, G. L., Li, D. (2016). Predicting future lung function decline in cystic fibrosis patients: Statistical methods and clinical connections. Pediatric Pulmonology, 51(2), $217-228$. doi: 10.1002/ppul.23357

8. Breuer, O., Caudri, D., Stick, S., Turkovic, L. (2018). Predicting disease progression in cystic fibrosis. Expert Review of Respiratory Medicine, 12(11), 905-917. doi: 10.1080/17476348.2018

9. Machado, B. C., Jacques, P.S., Penteado, L. P., Roth Dalcin P. T. (2018). Prognostic Factors in Adult Patients with Non-Cystic Fibrosis Bronchiectasis. Lung, 196(6), 691-697. doi: 10.1007/s00408-018-0165-z

10. Redondo, M., Keyt, Y., Chalmers, J. D. et al. (2016). Global impact of bronchiectasis and cystic fibrosis. Breathe (Sheff), 12(3), 222-235. doi: 10.1183/20734735.007516

11. Minov, J., Karadzinska-Bislimovska, J., Vasilevska, K. et al. (2015). Assessment of the non-cystic fibrosis bronchiectasis severity: the FACED Score vs the bronchiectasis severity index. The Open Respiratory Medicine Journal, 9, 46-51. doi: 10.2174/1874306401509010046

12. McDonnell, M. J., Aliberti, S., Goeminne, P. C. et al. (2016). Comorbidities and the risk of mortality in patients with bronchiectasis: an international multicentre cohort study. Lancet Respiratory Medicine, 412, 969-979. doi: 10.1016/S2213-2600(16)30320-4

13. Chalmers, J.D., Goeminne, P., Aliberti, S. et al. (2014). The bronchiectasis severity index. An international derivation and validation study. American Journal of Respiratory and Critical Care Medicine, 189(5), 576-585. doi: 10.1164/rccm.201309-15750C

14. Giangioppo, S., Kalaci, O., Radhakrishnan, A. et al. (2016). Complementary and alternative medicine use in children with cystic fibrosis. Complementary Therapies in Clinical Practice, 25, 68-71. doi: 10.1016/ j.ctcp.2016.08.006

Received: 25-Sep. - 2018

Accepted: 09-Dec. - 2018 